\title{
THE ROYAL SOCIETY OF CANADA
}

$\mathrm{T}$ HE Royal Society of Canada held its annual meeting at the University of Western Ontario, London, Ontario, during June 1-3. The scientific sections met separately as is the custom.

\section{Section III (Chemical, Mathematical and Physical Sciences)}

The presidential address was presented by Prof. R. L. Jeffery, who described the historical development and the impact of Fourier series on applied and pure mathematics. This was followed by a description of applications of Fourier series in physical problems (W. H. Watson), which together with the presidential address provided an informative and stimulating symposium on a subject of interest to all members of the section.

Following this symposium, the section divided into sub-sections to hear and discuss a total of 122 papers, arranged under the headings of spectroscopy and astrophysics, chemistry, mathematics, nuclear physics, general physies and solid state physics. The papers selected for presentation were not confined by a rigid definition of these headings, and therefore members of the Society were given an excellent review of the main fields of investigation being actively explored at the various research centres across Canada.

Spectroscopy and Astrophysics. This sub-section discussed fifteen papers on molecular spectra, hyperfine structure, Raman spectra, and the interpretation of certain stellar spectra. It included two theoretical papers, one on the calculation of vibrational transition probabilities and the other on the calculation of the dipole moment induced in an $\mathrm{H}_{2}-\mathrm{H}_{2}$ system during collision.

Chemistry. This sub-section, meeting in two sessions, was presented with twenty-six papers. A group of papers describing the successful synthesis of new series of pyrazolones and metameconine compounds, together with further synthesis of organic deuterium compounds, represented the work in this part of chemistry. Six papers dealt with various aspects of radioactive chemistry, isotopic constitutions and the occurrence of nuclear processes in Nature. Electrochemical studies on resin emulsions, ethyl chloride and the effect of adsorbates on activated carbon were described. The chemical kinetics of gas phase reactions, thermal decomposition, ion exchange and the quenching of resonance radiation were reported. A very complete study of the peats found in Quebec regarded as a potential source of chemical raw materials provided the desirable link with industrial chemistry. A dis. cussion of the orbital valence theory and a description of the motions and interactions of spheres and cylinders suspended in a liquid subjected to a velocity gradient were of particular interest to members of the other sub-sections.

Mathematics. The fourteen papers presented to this sub-section included six presentations of new theorems and properties relating to various topo- logical and function spaces. In particular the theory of $L$-spaces was considerably extended. Additions to the modular representation theory and the general properties of groups under substitution of formal power series, a discussion of absolute summability functions, hypergeometric functions, and two papers on further generalization of the Laplace transform method gave a sampling of the current interests in pure mathematics. The multiplicity of representations in sets of integers was discussed in two papers. Ordinary physical space received attention when it was shown that a classical theorem is equivalent to the fact that the closest possible packing of equal spheres about lattice points occurs when the centres form the face-centred cubic lattice.

Nuclear Physics. This sub-section received thirtyeight reports, of which twenty-six were read at its two sessions, and the remaining thirteen reported by titie. The wide variety of techniques and reactions used, nuclei studied and properties measured preclude any convenient classification of the papers.

The results of cosmic ray studies were reported in four papers while two others presented problems of particle identification in photographic emulsions. Descriptions of new technical advances included an apparatus for the observation of spin echoes, the stabilization of a Van de Graaff generator, a singlecrystal scintillation spectrometer, a three-erystal pair spectrometer, coincidence circuits with resolving time of $\sim 10^{-11}$ sec. and an improved beta-ray spectrometer.

A description of neutron diffraction in liquid oxygen, nitrogen and argon, the successful testing of a new method of nuclear spin determination and five theoretical papers on coupling, resonance, spin and magnetic moment calculations completed the programme of this sub-section.

General Physics. Of the twelve papers presented to this sub-section, eight dealt with radio physics problems: radio investigation of the aurora, solar noise, design of filters, effect of matching on crystal parameters, microwave diffraction and microwave spectroscopy. Members were shown that the thickness of irregularly shaped particles determined by shadow-casting methods is not necessarily accurate. Three papers were reported by title.

Solid State Physics. The fourteen papers presented to this sub-section included all those devoted to low-temperature theory and problems; four on studies concerned with liquid helium, two on superconductivity, paramagnetic resonance and thermoelectricity. Other theoretical papers described an alternative solution to the Ehrenfest problem, the effect of assumed anharmonicity in the classical linear chain with nearest-neighbour interaction, the reverse saturation current of germanium rectifiers, the self-consistent field of $\mathrm{Au}^{+}$, and the relation of vapour density to snow crystal type. Reports on the tensile strength of liquid nitrogen and observations of the pattern of snow trails in seeded showers were given.
A. D. Misener 


\section{Section IV (Geological Sciences)}

The twenty-one papers given before Section IV included most branches of the geological sciences. J. T. Wilson discussed the earth as a heat engine, and its operation under the laws of physics; J. A. Jacobs reviewed the composition of the core of the earth and how it could have become solid through losis of heat by convection, though only conduction appears necessary. Some characteristics of grabens, rifts, major wrench faults and straight island chains, their agreement with E. M. Anderson's explanation of wrench faults and their occurrences were discussed by J. T. Wilson. H. S. Heaps gave a theoretical analysis of 'downpunching', with the stresses produced in the outer crust of the earth by the weight of a cylinder on its surface, and showed that some of the results apply to the load imposed by an ice cap. The interpretation of structural features, seen in aerial photographs of south-eastern Ontario, was discussed by A. Burlinson. E. S. Moore gave an account of the structural history of the Porcupine Gold area revealed by detailed mapping.

Two papers described glacial features mapped from aerial photographs in the vast territories of the north and their interpretation, that by M. J. Downie, A. G. Evans and J. T. Wilson dealt with the region between the Mackenzie River and Hudson Bay, while that by M. C. V. Douglas and R. N. Drummond covered Ungava.

Three papers were devoted to the determination of the ages of rocks : first, an account of the branching ratio of potassium-40 by R. D. Russell, H. A. Shilliber and A. K. Mousuf; second, the determination of the ages of lead ores from their isotopic constitutions, by R. M. Farquhar, R. D. Russell and J. T. Wilson; and third, the isotopic constitution of the Sudbury galenas, by R. D. Russell, R. M. Farquhar and G. L. Cumming. J. F. Henderson gave a new and more complete explanation of the formation of pillow lavas and breccias of the Precambrian Shield. M. E. Wilson described the pre-Timiskaming unconformity in the Rouyn-Beauchastel area. C. Faessler described the surface alteration of some ore deposits from Montmagny and Bellechasse counties, Quebec, and some rare minerals from them. The origin and structure of the pyritic ore-bodies of Algoma, east of Goudreau, and their connexion with the Algoma granite, were discussed by G. V. Douglas. An account of the origin of the Nova Scotian gypsum and anhydrite deposits was given by N. R. Goodman.

The paper by H. V. Warren, R. E. Delauvault and D. G. Routley described the detection of traces of molybdenum in vegetation growing where the rocks contain the metal. A. R. Byers demonstrated that the Missi Series of the Amisk Lake area, northern Saskatchewan, was probably laid down during the folding of the underlying rocks. A paper of great importance in Precambrian geology was that by J. E. Thomson. This paper shakes the foundation of present conceptions of the Precambrian stratigraphy in the region west of Sudbury, which has long been regarded as a type and classical section of the Precambrian in North America. It focuses a critical light upon the past work in the region, and offers constructive ideas as to how the problems raised may be tackled. F. F. Osborne described a peculiar concretion conglomerate in the Charny sandstone and discussed its origin. L. S. Russell described the discovery of a new freshwater fauna, including terrestrial gastropods and small mammalian forms, and showed that it dates the Kishenehn formation of south-eastern British Columbia as uppermost Eocene and necessitates some revision. of ideas on the history of the southern Rocky Mountains of Canada. H. S. Bostock

\section{Section V (Biological Sciences)}

W. A. Clemen's presidential address on "Some Fundamental Problems in the Biology of Pacific Salmon" dealt with the systematics, phylogeny, distribution and migrations of Oncorhynchus. In discussing migration, the author referred particularly to endocrine and associated behaviour-pattern changes in relation to cyclic environmental factors. E. G. D. Murray's Flavelle medallist's address "The Story of Listeria" indicated problems in comparative pathology, physiology, biochemistry of lipids and histogenesis of mononuclear leucocytes arising from the discovery of a bacterial disease characterized by monocytosis, focal necrosis and oedema, occurring on all continents and in nineteen animal species (including man) in various somewhat species-restricted forms without differentiation of the causative bacterium. Three other papers were also delivered at the first general session. "On the Nutritional Requirements of Young Children", by T. Allen, A. V. MacLeod and E. G. Young, reported conclusions from two surveys comprising 156 children 1-6 years of age, in which nutrition assessed from physical, anthropometric, laboratory and radiographic observations was correlated with dietary consumption of essential nutrients. P. Dansereau discussed "Interpretation of the Postglacial Pine Period in Eastern North America". $\mathrm{He}$ considered alternative hypotheses, respectively attributing stages of abundant Pinus pollen during this epoch to environmental factors and to adaptation of the prevalent species, and then reviewed the evidence provided in six specific instances, by geology, climatology, evolution, genetics, taxonomy, ecology and sociology. Finally, W. Radforth, in "The Use of Plant Materials in Recognizing Northern Organic Terrain Types", described microfossil studies combined with form analyses of associated living vegetation as aids in the accurate classification of terrain for ground and air mapping.

The second general session consisted of a symposium on "Recent Approaches to the Control of Diseases and Pests in Plant and Animal Life". H. Martin reviewed chemical contributions resulting from the discovery and delimitation (particularly in respect of mammalian toxicity) of biological activity in synthetic compounds, exemplified by DDT and $2: 4-D$. J. M. Cameron discussed the variable results achieved in forest insect control by chemicals and by biological methods, utilizing sylviculture, parasites and predators. F. B. Hutt illustrated the importance of genetic differences in resistance of animals (including man) to infection, and their relation to the control of specific diseases. E. G. D. Murray selectively reviewed recent advances in medical bacteriology, indicating some findings of general biological significance. He also suggested lines of fruitful investigation, such as determination of the specific cellular functions affected by antibiotics.

In a short summary, reference can be made to only a few of the more specialized papers presented at the meetings of sub-sections. In botany and zoology, G. N. Irvine, W. Bushuk and J. A. Anderson reported first-order reaction kinetics for crude 
catalase extracts from wheat which, unlike the crystalline enzyme, were not activated by the hydrogen peroxide substrate. P. V. Vittorio and G. Krotkov discussed the synthesis of sucrose and starch in detached tobacco leaves infiltrated with carbon-14-labelled glucose and glucose-1-phosphate. They concluded that the fructose moiety of sucrose arose from infiltrating glucose and not from free fructose, but that infiltrated radioactive sugars contributed only a small amount of their activity to starch.

D. E. Wells reported the discovery of Ascocybe, a new genus of primitive Ascomycetes, as a common saprophyte on wood, while M. Raymond described a noteworthy new hybrid between Eriophorum angustifolium and $E$. chamissonis. L. Butler summarized the results of an experiment with large and small strains of mice involving inbreeding and selection to increase the size of the former strain and decrease that of the latter. No effect of inbreeding on vigour was noted. In the large strain, experimental selection was neutralized by opposed effects of natural selection. In the small strain effects of natural selection were dominant, and bodysize actually increased in each generation.

In physiology and medical sciences, W. R. Campbell described a new method of photometric estimation of serum calcium, based on Schwarzenbach's reaction and promising routine rapidity and precision. F. T. English and R. L. Noble demonstrated that although either periodic acid or an aqueous extract of Lithospermum corceum may induce inactivation of human chorionic gonadotrophin in vitro, the mode of inactivation differs when judged by histological examination of the ovaries of treated animals. W. H. Cook and C. V. Luzena discussed ice propagation in model systems of solutions and membranes, in relation to the ability of living cells to survive freezing. Discontinuous behaviour is favoured by low membrane porosity, rapid cooling and increased concentration of solutes in the aqueous phase; supercooling and nucleation ahead of the ice front can be demonstrated in sucrose and gelatin solutions. C. A. Mitchell presented data indicating that at least two viruses can propagate themselves within the bovine mammary gland; resulting locally produced neutralizing antibodies may be found in both the blood and milk serum. J. Tuba and M. I. Robinson' reported that rat intestinal alkaline phosphatase consists of an adaptive portion varying with the dietary state and a non-adaptive fraction remaining constant even during prolonged fasting; the former is probably translocated lymphatically during fat absorption, thus elevating serum phosphatase levels. A. H. Hutchinson, V. H. Turnbridge and M. Elvin submitted photomicrographic evidence for mitosis, syngamy and meiosis in Bacillus subtilis (the cytological cycle being completed in two hours at $40^{\circ} \mathrm{C}$.), and compared the observed structural detail of euchromatic progression with the cytology of other forms. N. H. GRACE J. W. Hopkins

\section{New Fellows}

Six new fellows were elected to Section III : G. A. Adams, H. J. Bernstein, I. Halperin, M. Kulka, M. S. Macphail, J. S. Marshall ; four to Section IV : N. Campbell, Y. O. Fortier, J. W. Watson, L. J. Weeks; and six to Section V: J. A. Dauphinee, C. C. Heimburger, A. G. McCalla, J. H. Orr, J. H. Quastel, E. H. Strickland.

\section{PHOTOELECTRIC RAINDROP SPECTROMETER}

$\mathrm{D}$ ETERMINATION of the frequency distribution of the diameter of raindrops in relation to the rate of rainfall is an important problem of meteorological measurement. Knowledge of this distribution is important in the major scientific problem of the formation of raindrops and in such practical matters as protection of aircraft from ice accretion. Several methods have been used hitherto, such as measuring the size of the pellets formed when the drops fall into fine flour, the diameter of splashes on filter paper, or the magnitude of the noise produced when the drop hits a microphone. All had serious disadvantages, such as uncertainty of calibration or lack of flexibility in use in natural rain in which the rate of fall sometimes changes quickly.

Now, in the October number of the Quarterly Journal of the Royal Meteorological Society, B. J. Mason and R. Ramanadham, of the Department of Meteorology, Imperial College of Science and Technology, London, describe an entirely new apparatus - the photoelectric raindrop spectrometer-which is based on the scattering of light by the drops. A parallel beam of light of horizontal axis is produced, and the drops falling through a rhombus-shaped section in this beam of area $72 \mathrm{~cm}^{2}$ scatter light into the cathode of a photo-multiplier cell. The voltage produced by the light pulse is suitably amplified and recorded and the results interpreted from calibration with drops of known size. The apparatus has the great advantage that it records continuously and takes account without difficulty of obliquely falling drops and of changes in the rate of fall. The probability of two drops falling through the area in natural rain at the same time to give overlapping impulses on the recorder is so small that it can be entirely neglected.

A comparison of this new apparatus with older, more clumsy methods has shown very good agreement. A few records are given in the paper. A series taken during showers shows that the drop-frequency curve had two modes in the heavier rain. The rates of fall varied from $2 \cdot 43 \mathrm{~mm}$./hr. to $0 \cdot 22$ $\mathrm{mm}$. $/ \mathrm{hr}$. All had a mode of drop-diameter at $0.9 \mathrm{~mm}$.; the $0.22 \mathrm{~mm}$. $/ \mathrm{hr}$. rain had no second mode, and the second modes were $1.4 \mathrm{~mm}$. for the rate of $0.66 \mathrm{~mm} . / \mathrm{hr}$, and $1.6 \mathrm{~mm}$. for the rates of 1.26 and $2.43 \mathrm{~mm}$. $/ \mathrm{hr}$. The amount of rainfall recorded by a rainfall recorder over several minutes during a light shower and the amount deduced from the spectrometer readings agreed to within 5 per cent. The raindrop spectrometer is to be used in conjunction with a $3-\mathrm{cm}$. radar in the study of condensation processes.

\section{NATIONAL CENTRAL LIBRARY, LONDON REPORT FOR $1952-53$}

HE thirty-seventh annual report of the executive
committee of the National Central Library,
London, covering the year ended February 28, 1953,
records an increase in the Treasury grant-in-aid from
$£ 27,250$ during $1951-52$ to $£ 31,250$. The funds at the
Trustees' disposal were insufficient to cover the cost
of the essential reinforcements in the east wing of 